\title{
Value of Follow-Up Chest Computed Tomography in the Surveillance of Patients with Hepatocellular Carcinoma
}

\author{
Ahmed W Moawad (1D' \\ Khaled M Elsayes (D) \\ Farah Benamar' \\ Kundan Rao (D) \\ Jia Sun ${ }^{2}$ \\ Janio Szklaruk (DD
}

'Department of Abdominal Imaging, Division of Diagnostic Imaging, The University of Texas MD Anderson Cancer Center, Houston, TX, USA; ${ }^{2}$ Department of Biostatistics, The University of Texas MD Anderson Cancer Center, Houston, TX, USA
Correspondence: Janio Szklaruk Department of Abdominal Imaging, Division of Diagnostic Imaging, Unit I473, The University of Texas MD Anderson Cancer Center, 1515 Holcombe Blvd, Houston, TX 77030, USA

Tel +I (7I3) 745-3230

$\mathrm{Fax}+\mathrm{I}(832) 750-1633$

Email JSzklaru@mdanderson.org
This article was published in the following Dove Press journal: Journal of Hepatocellular Carcinoma

Purpose: To evaluate the value of follow-up chest CT in the surveillance of HCC patients. Background: Imaging guidelines for the surveillance of hepatocellular carcinoma (HCC) patients recommend multiple follow-up computed tomography (CT) examinations of the chest, abdomen, and pelvis. Imaging studies are a major driver of rising healthcare costs. The appropriate use of imaging studies must be evaluated to provide valued health care.

Methods: We reviewed the radiology reports of baseline and follow-up chest, abdominal, and pelvic CT examinations of HCC patients. We categorized the incidence of malignancy in the chest and abdomen for the baseline and follow-up examinations. We also categorized the follow-up examinations as showing improved disease, stable disease, or disease progression. We correlated any progression of disease in the chest with progression of disease in the abdomen. We determined the extent to which disease progression in the chest occurred alongside that in the abdomen. Descriptive statistical analysis was carried out using $\mathrm{R}$ (version 3.5.2, R Development Core Team).

Results: Of the 226 patients included in our study, only 7 (3\%) had disease progression in the chest without corresponding disease progression in the abdomen and pelvis on follow-up CT. Only $1.8 \%$ of patients with disease progression in the chest had a negative CT chest at baseline.

Conclusion: Follow-up chest CT has limited benefit in the surveillance of HCC patients, especially those with negative baseline chest CT findings.

Keywords: malignancy, imaging, staging, metastases, benefit, cost-effective

\section{Introduction}

Hepatocellular carcinoma (HCC) is the third most common cause of cancer-related death worldwide, with almost 30,000 new cases diagnosed annually in the United States alone. ${ }^{1}$ The incidence of HCC is predicted to increase steeply throughout the next decade owing to sustained increase in rates of obesity and obesity-related health problems. ${ }^{2}$

Imaging plays a major role in the surveillance of HCC patients. ${ }^{3}$ The current National Comprehensive Cancer Network guidelines for the surveillance of HCC patients include imaging with computed tomography (CT) of the chest and multiphasic CT or magnetic resonance imaging (MRI) of the abdomen and pelvis every 3-6 months for 2 years and then every 6-12 months thereafter. ${ }^{4}$ CT imaging of the chest, abdomen and pelvis results in excessive radiation exposure to the patient. Evaluation of the value of imaging is important to reduce possible unnecessary exposure to 
radiation. When combining the CT imaging of the chest, abdomen and pelvis in a single examination there is an increase in the total number of images required for interpretation by the radiologists. Reducing unnecessary imaging should result in reducing radiologist's fatigue that may lead to diagnostic errors. ${ }^{5}$ Finally, imaging is also considered to be the most important factor driving the rise of healthcare costs in the United States. ${ }^{6}$ Therefore, it is important to assess the benefit of imaging in each clinical scenario.

Abdominal CT or MRI with a liver protocol is clearly indicated for the surveillance of localized HCC in the liver. However, the role of additional imaging beyond the abdomen remains unclear. Some researchers have recommended the discontinuation of pelvic imaging. ${ }^{7}$ Others have reported the low incidence of findings of extrahepatic disease, including that in the chest, in HCC patients. ${ }^{8,9}$

To our knowledge, no study has assessed the role of follow-up chest CT in the surveillance of HCC patients. There is a need for evidence-based medicine to support the current guidelines for surveillance of patients with HCC with serial CT chest examinations. The purpose of the present study is to evaluate the benefit of follow-up chest $\mathrm{CT}$ in HCC patients. We hypothesized that, following a baseline chest CT examination, follow-up chest CT has a limited role in the surveillance of HCC patients, especially those with a negative baseline chest $\mathrm{CT}$ examination.

\section{Materials and Methods}

\section{Patient Population}

This retrospective study was approved by our institution's (University of Texas MD Anderson Cancer Center) Institutional Review Board, and informed consent was waived because of the retrospective nature of the study. The data accessed complied with relevant data protection and privacy regulations. We searched our institution's electronic health record (EHR) to identify patients who were diagnosed with HCC from March 2016 through April 2019 and who underwent baseline CT examination of the abdomen and chest and follow-up CT examination of the same areas at least 6 weeks later. The radiology reports, laboratory data, and demographics of the patients who met the study's inclusion criteria were extracted from the EHR.

\section{Imaging Techniques}

All CT examinations were performed using multi-detector CT systems from GE Healthcare (Chicago, IL, USA) or Siemens Healthineers (Erlangen, Germany). CT liver protocols were performed with intravenous contrast. With the use of a bolus-tracking technique, the late arterial phase was acquired 17 seconds after a 100-HU threshold was reached at the celiac artery. This is approximately at $25 \mathrm{~s}$ after the initiation of contrast. The portal venous phase of the abdomen and pelvis was acquired approximately 60-70 seconds after contrast administration. The chest, abdomen, and pelvis were imaged approximately 3 minutes after contrast administration. All patients also underwent non-contrast-enhanced CT of the liver.

\section{Data Analysis}

Data on the location of disease in the abdomen and chest were extracted from the radiology reports of the baseline and follow-up CT examinations. For both the baseline and follow-up CT examinations, metastatic disease was categorized as occurring in 1 of 3 locations: 1) chest, 2) liver, or 3) abdomen (extrahepatic). The results of the follow-up CT examinations were categorized as showing 1) stable disease, 2) improved disease, or 3) disease progression. The radiology report was used to categorize disease status. The reports with indeterminate findings were not considered malignant. Only reports of definite metastatic disease were considered malignant. For patients whose follow-up CT examinations showed disease progression in the chest, we assessed with follow-up CT findings in the liver and/or abdomen. Clinical and tumor characteristics were summarized using frequencies and percentages. Descriptive statistical analysis was carried out using R-statistics (version 3.5.2, R Development Core Team).

\section{Results}

\section{Patient Demographics}

Our initial search of the institutional database identified 736 HCC patients. Of these 736 patients, 486 were excluded because they did not undergo chest $\mathrm{CT}$ at or within three days of the abdominal examination; 19 were excluded because they had multiple primary malignancies; and five were excluded because they underwent follow-up CT less than 6 weeks after baseline CT. Thus, the study included 226 patients (37 women and 189 men) (Figure 1). The mean age was 65 years (standard deviation, 9 years).

\section{Radiology Results Baseline Studies}

Baseline CT revealed that 36 patients (16\%) had metastatic disease in the chest, $40(17.7 \%)$ had extrahepatic metastatic disease, and 193 (85\%) had disease burden in 
736 patients (identified from institutional EHR)

486 patients excluded - Absence of chest CT Absence of abdominal CT

\section{0 patients}

\section{9 patients excluded} More than one primary malignancy

\section{1 patients}

\section{5 patients excluded} Follow-up CT $<6$ weeks after baseline CT

\section{6 patients}

\section{(included in study)}

Figure I Patient selection flowchart.

the liver (Table 1). Seventy-six patients had extrahepatic disease in the chest or abdomen (33.6\%).

\section{Follow-Up Studies}

Follow-up CT revealed that 38 (17\%) patients had disease progression in the chest, $92(41 \%)$ had disease progression in the liver (Table 2), and 49 (22\%) had extrahepatic disease progression in the abdomen (Table 3). Forty-six (20.4\%) and eighty-eight (38.9\%) had improved or stable disease in the liver, respectively. Fourteen patients had improved extrahepatic disease in the abdomen and 163 had stable extrahepatic disease in the abdomen. The mean time to follow-up CT was 22 weeks (range, $6-110$ weeks).

Follow-up CT also revealed that of the 38 patients who had progression in the chest, 25 also had progression in the liver (Table 2), 16 also had extrahepatic progression in the abdomen (Table 3), and 31 had extrahepatic or hepatic progression in the abdomen
Table I Baseline Computed Tomography Findings of Extrahepatic Hepatocellular Carcinoma Metastasis in Either the Chest or Abdomen

\begin{tabular}{|l|l|}
\hline Finding & $\begin{array}{l}\text { Number of } \\
\text { Patients }\end{array}$ \\
\hline $\begin{array}{l}\text { Chest (36 patients) } \\
\text { Osseous metastasis }\end{array}$ \\
Pulmonary nodules & 3 \\
Lymphadenopathy (mediastinal, hilar) & 23 \\
\hline Abdomen (40 patients) & 10 \\
Osseous metastases & \\
Peritoneal implants & 5 \\
Adrenal nodules & 18 \\
Abdominal lymphadenopathy & 3 \\
Pancreatic metastasis & 12 \\
\hline Liver & 2 \\
Disease burden & \\
\hline
\end{tabular}

Table 2 Findings of Follow-Up Computed Tomography (CT) of the Chest and Liver

\begin{tabular}{|l|l|l|}
\hline $\begin{array}{l}\text { Follow-Up Chest CT } \\
\text { Findings }\end{array}$ & $\begin{array}{l}\text { Follow-Up Liver } \\
\text { CT Findings }\end{array}$ & $\begin{array}{l}\text { Number of } \\
\text { Patients } \\
\text { (\%) }\end{array}$ \\
\hline Improved disease (9 patients) & $\begin{array}{l}\text { Improved disease } \\
\text { Stable disease } \\
\text { Disease progression }\end{array}$ & $\begin{array}{l}5(2.2) \\
2(0.9) \\
2(0.9)\end{array}$ \\
\hline Stable disease (179 patients) & Improved disease & $37(16.4)$ \\
& Stable disease & $77(34)$ \\
& Disease progression & $65(28.8)$ \\
\hline Disease progression (38 & Improved disease & $4(1.8)$ \\
patients) & Stable disease & $9(4.0)$ \\
& Disease progression & $25(11)$ \\
\hline
\end{tabular}

Abbreviation: $\mathrm{CT}$, computed tomography.

(Table 4). Only seven patients had progression in the chest without disease progression below the diaphragm. Of the 38 patients who had progression in the chest on follow-up CT, 16 had metastatic disease in the chest at baseline CT. Of these 16 patients, 15 also had progression in either the liver or abdomen on follow-up CT (Tables 2-4).

Twenty-two patients had progression in the chest on follow-up CT with no metastatic disease in the chest at baseline CT. Of 22 patients who had a negative baseline CT, 5 had progression in the chest with a negative baseline $\mathrm{CT}$ and without corresponding progression of disease in the liver or abdomen on follow-up CT $(2.2 \% ; 5 / 226)$. 
Table 3 Findings of Follow-Up Computed Tomography (CT) of the Chest and Abdomen

\begin{tabular}{|l|l|l|}
\hline $\begin{array}{l}\text { Follow-Up Chest } \\
\text { CT Findings }\end{array}$ & $\begin{array}{l}\text { Follow-Up Abdominal } \\
\text { CT Findings }\end{array}$ & $\begin{array}{l}\text { Number of } \\
\text { Patients (\%) }\end{array}$ \\
\hline $\begin{array}{l}\text { Improved disease } \\
\text { (9 patients) }\end{array}$ & $\begin{array}{l}\text { Improved or stable disease } \\
\text { Disease progression }\end{array}$ & $\begin{array}{l}9(4) \\
0(0.0)\end{array}$ \\
\hline $\begin{array}{l}\text { Stable disease } \\
\text { (I79 patients) }\end{array}$ & $\begin{array}{l}\text { Improved or stable disease } \\
\text { Disease progression }\end{array}$ & $\begin{array}{l}146(64.3) \\
33(14.6)\end{array}$ \\
\hline $\begin{array}{l}\text { Disease progression } \\
\text { (38 patients) }\end{array}$ & $\begin{array}{l}\text { Improved or stable disease } \\
\text { Disease progression }\end{array}$ & $\begin{array}{l}22(10) \\
16(7.1)\end{array}$ \\
\hline
\end{tabular}

Abbreviation: $\mathrm{CT}$, computed tomography.

Table 4 Findings of Follow-Up Computed Tomography (CT) of the Chest and of the Liver or Abdomen

\begin{tabular}{|c|c|c|}
\hline $\begin{array}{l}\text { Follow-Up Chest } \\
\text { CT Findings }\end{array}$ & $\begin{array}{l}\text { Follow-Up Liver or } \\
\text { Abdominal CT Findings }\end{array}$ & $\begin{array}{l}\text { Number of } \\
\text { Patients (\%) }\end{array}$ \\
\hline $\begin{array}{l}\text { Improved disease } \\
\text { ( } 9 \text { patients) }\end{array}$ & $\begin{array}{l}\text { Improved or stable disease } \\
\text { Disease progression }\end{array}$ & $\begin{array}{l}7(3.1) \\
2(0.9)\end{array}$ \\
\hline $\begin{array}{l}\text { Stable disease } \\
\text { (179 patients) }\end{array}$ & $\begin{array}{l}\text { Improved or stable disease } \\
\text { Disease progression }\end{array}$ & $\begin{array}{l}95(42.0) \\
84(37.2)\end{array}$ \\
\hline $\begin{array}{l}\text { Disease progression } \\
\text { (38 patients) }\end{array}$ & $\begin{array}{l}\text { Improved or stable disease } \\
\text { Disease progression }\end{array}$ & $\begin{array}{l}7(3.1) \\
31(13.7)\end{array}$ \\
\hline
\end{tabular}

Abbreviation: $\mathrm{CT}$, computed tomography.

In summary, 7 patients $(3.1 \%$; $7 / 226)$ had progression in the chest without corresponding progression in the liver or abdomen on follow-up CT.

\section{Discussion}

To our knowledge, we are the first to evaluate the use of follow-up chest CT in the surveillance of HCC patients. The results of the present study confirmed our hypothesis that follow-up chest CT is of limited value in the surveillance of HCC patients. Only 3\% of our patient population had disease progression in the chest without corresponding progression in the liver or abdomen on follow-up CT. Furthermore, only $2.2 \%$ of the patients who had a negative baseline chest CT examination had disease progression in the chest without a corresponding progression in the liver or abdomen on follow-up CT.

Others have assessed the incidence of extrahepatic disease burden in HCC patients. Leong et al reported that lung is the most common site of extrahepatic spread of $\mathrm{HCC}$ and that its incidence infrequent $(12.6 \%) .{ }^{10} \mathrm{Kanda}$ et al reported that the lifetime annual incidence rate of extrahepatic metastasis is approximately $2.5 \%$. The reported incidence of extrahepatic metastasis is as high as $19.5 \%$ at 7 years. $^{8}$ Jin et al, evaluating the role of chest $\mathrm{CT}$ in the staging workup of HCC patients, found that $2.9 \%$ of patients had metastatic disease in the chest but not the liver. ${ }^{11}$ Others have also reported a limited role of the chest CT examination in HCC patients. ${ }^{12,13}$ These reports did not correlate the disease progression in the abdomen with the progression of the disease in the chest. $^{7,9-12}$

In the present study, baseline CT revealed a prevalence $(76 / 226 ; 33.6 \%)$ of extrahepatic metastatic disease at baseline. The incidence of extrahepatic disease in the present study (33.6\%) was larger than that reported previously. ${ }^{7,9-12}$ This may have been because our study was conducted at a tertiary cancer center, whose patients tend to have more advanced disease.

Follow-up CT revealed that 38 patients had progression in the chest and that 31 of these 38 patients had corresponding progression in the abdomen. These findings suggest that abdominal CT alone should be sufficient to detect disease progression in most patients.

Our study had some limitations. We extracted data from the original radiology reports, not from a second review of the CT examinations. However, extraction of data from radiology reports approximates the clinical practice for making treatment and other clinical decisions. We did not stratify the patients according to their clinical disease stage, tumor burden, or tumor size. It may seem possible to consider that advanced stage and increased tumor burned may result in higher incidence of disease progression. However, we expect to see the progression in the abdomen and not chest-only disease progression. The very low incidence of chest only progression with a negative baseline CT will probably remain small. Another limitation was that the time lapse between the patients' baseline CT and follow-up CT examinations were relatively short. However, we found that some patients had disease progression as few as 6 weeks after baseline CT. Although a longer follow-up period could yield more disease burden, we expect to be present in the liver and extrahepatic, and not chest-only disease progression. Finally, a substantial portion of our patient population had a high disease burden. When extended to the larger population with less disease burden, we anticipate a lower incidence of extrahepatic disease and/or chest-only progression and anticipate a smaller percentage of chest only progression. 
In conclusion, the results of this study, in combination with those of prior reports, suggest that follow-up chest CT has limited benefit in HCC patients.

\section{Acknowledgments}

We thank Joe Munch from the Department of Scientific Publications, Research Medical Library, at The University of Texas MD Anderson Cancer Center, and Ms. Palencia Lewis for their help in the preparation of documents. This study was supported by the National Institutes of Health/ National Cancer Institute (Cancer Center Support Grant P30 CA016672); resources from the Biostatistics Resource Group were used.

\section{Disclosure}

All authors declare that they have nothing to disclose.

\section{References}

1. Kohn CG, Singh P, Korytowsky B, et al. Humanistic and economic burden of hepatocellular carcinoma: systematic literature review. $\mathrm{Am}$ $J$ Manag Care. 2019;25(2Spec No.):SP61-SP73.

2. Shiels MS, Engels EA, Yanik EL, McGlynn KA, Pfeiffer RM, O'Brien TR. Incidence of hepatocellular carcinoma among older Americans attributable to hepatitis C and hepatitis B: 2001 through 2013. Cancer. 2019;125(15):2621-2630.

3. Ayuso C, Rimola J, Vilana R, et al. Diagnosis and staging of hepatocellular carcinoma (HCC): current guidelines. Eur $J$ Radiol. 2018;101:72-81. doi:10.1016/j.ejrad.2018.01.025
4. Network NCC. Available from: https://www.nccn.org/professionals/ physician_gls/pdf/hepatobiliary.pdf. Accessed November 3, 2020.

5. Stec N, Arje D, Moody AR, Krupinski EA, Tyrrell PN. A systematic review of fatigue in radiology: is it a problem? AJR Am J Roentgenol. 2018;210(4):799-806. doi:10.2214/AJR.17.18613

6. Papanicolas I, Woskie LR, Jha AK. Health care spending in the United States and other high-income countries. JAMA. 2018;319 (10):1024-1039. doi:10.1001/jama.2018.1150

7. Szklaruk J, Kaya D, Wei W. Evaluation of the added value of imaging the pelvis in patients with hepatocellular cancer. J Gastroenterol Hepatol. 2018;33(2):500-502. doi:10.1111/jgh.13847

8. Kanda M, Tateishi R, Yoshida H, et al. Extrahepatic metastasis of hepatocellular carcinoma: incidence and risk factors. Liver Int. 2008;28(9):1256-1263. doi:10.1111/j.1478-3231.2008.01864.x

9. Abbas A, Medvedev S, Shores N, et al. Epidemiology of metastatic hepatocellular carcinoma, a nationwide perspective. Dig Dis Sci. 2014;59(11):2813-2820. doi:10.1007/s10620-014-3229-9

10. Leong PW, Pua U, Lim KS. Routine staging using chest computed tomography in workup of treatment-naive hepatocellular carcinoma prior to locoregional therapy: is there a need? Ann Acad Med Singapore. 2017;46(7):282-286.

11. Jin YJ, Lee HC, Lee D, et al. Role of the routine use of chest computed tomography and bone scan in staging workup of hepatocellular carcinoma. J Hepatol. 2012;56(^):1324-1329.

12. Koneru B, Teperman LW, Manzarbeitia C, et al. A multicenter evaluation of utility of chest computed tomography and bone scans in liver transplant candidates with stages I and II hepatoma. Ann Surg. 2005;241(4):622-628. doi:10.1097/01.sla.0000157267.27356.80

13. Davis SD. CT evaluation for pulmonary metastases in patients with extrathoracic malignancy. Radiology. 1991;180(1):1-12. doi:10.1148/ radiology.180.1.2052672
Journal of Hepatocellular Carcinoma

\section{Publish your work in this journal}

The Journal of Hepatocellular Carcinoma is an international, peerreviewed, open access journal that offers a platform for the dissemination and study of clinical, translational and basic research findings in this rapidly developing field. Development in areas including, but not limited to, epidemiology, vaccination, hepatitis therapy, pathology

\section{Dovepress}

and molecular tumor classification and prognostication are all considered for publication. The manuscript management system is completely online and includes a very quick and fair peer-review system, which is all easy to use. Visit http://www.dovepress.com/ testimonials.php to read real quotes from published authors. 